Research Paper

\title{
Plasma levels of the tissue inhibitor matrix metalloproteinase- 3 as a potential biomarker in oral cancer progression
}

\author{
Chun-Wen Su ${ }^{1 *}$, Bo-Feng Su ${ }^{2 *}$, Whei-Ling Chiang ${ }^{3}$, Shun-Fa Yang ${ }^{1,4}$, Mu-Kuan Chen ${ }^{1,5}$, Chiao-Wen Lin ${ }^{6,7 凶}$ \\ 1. Institute of Medicine, Chung Shan Medical University, Taichung, Taiwan. \\ 2. Department of Orthopedics, Changhua Christian Hospital, Changhua, Taiwan. \\ 3. School of Medical Laboratory and Biotechnology, Chung Shan Medical University, Taichung, Taiwan. \\ 4. Department of Medical Research, Chung Shan Medical University Hospital, Taichung, Taiwan. \\ 5. Department of Otorhinolaryngology-Head and Neck Surgery, Changhua Christian Hospital, Changhua, Taiwan. \\ 6. Institute of Oral Sciences, Chung Shan Medical University, Taichung, Taiwan. \\ 7. Department of Dentistry, Chung Shan Medical University Hospital, Taichung, Taiwan. \\ *These authors contributed equally to the work. \\ $\triangle$ Corresponding author: Chiao-Wen Lin, PhD., Institute of Oral Sciences, Chung Shan Medical University, 110 Chien-Kuo N. Road, Section 1, Taichung 402, \\ Taiwan. Telephone: +886-4-24739595 ext. 34255; Fax: +886-4-24723229; E-mail: cwlin@csmu.edu.tw. \\ (c) Ivyspring International Publisher. This is an open access article distributed under the terms of the Creative Commons Attribution (CC BY-NC) license \\ (https://creativecommons.org/licenses/by-nc/4.0/). See http://ivyspring.com/terms for full terms and conditions.
}

Received: 2016.07.29; Accepted: 2016.11.01; Published: 2017.01.01

\begin{abstract}
Oral cancer is the most common malignancy with poor prognosis and is the fourth most common cancer in men in Taiwan. The tissue inhibitor of metalloproteinase-3 (TIMP3) acts as a tumor suppressor gene by inhibiting the growth, angiogenesis, migration, and invasion of cancer cells. However, few studies have examined the association of plasma TIMP3 levels with oral squamous cell carcinoma (OSCC), and the role of plasma TIMP3 levels in OSCC progression is still unclear. We measured the plasma TIMP3 levels of 450 OSCC patients and 64 healthy controls by using a commercial enzyme-linked immunosorbent assay. We also analyzed TIMP3 mRNA levels of 328 OSCC patients and 32 normal tissues from The Cancer Genome Atlas (TCGA) dataset. Our results revealed that plasma TIMP3 levels were significantly lower in patients with OSCC than in healthy controls $(p<0.001)$. Moreover, plasma TIMP3 levels in patients with OSCC were significantly associated with the tumor stage and tumor status but not with the lymph node status, metastasis, and cell differentiation. To verify our findings, we also examined TCGA bioinformatics database and discovered similar results for the association with the pathological stage of OSCC. In conclusion, our results suggest that plasma TIMP3 is a potential biomarker for predicting the tumor stage and $T$ status in patients with OSCC.
\end{abstract}

Key words: TIMP3, oral squamous cell carcinoma, biomarker.

\section{Introduction}

Oral cancer is the fourth most common malignancy in men and the sixth leading cause of cancer-related deaths in Taiwan [1]. Oral squamous cell carcinoma (OSCC) accounts for approximately $90 \%$ of oral cancers. Failure to control the primary cancer, poor prognosis, high recurrence rate, and lymph node metastasis are the main causes of death in patients with OSCC [2]. Therefore, various proteins from the tissue, serum, and saliva have been established as biomarkers to enable the early detection of OSCC progression. For example, the tumor protein p53, which regulates the cell cycle, is associated with overall survival [3]. Other proteins such as the vascular endothelial growth factor (VEGF)-A, VEGF-C, E-cadherin, focal adhesion kinases, metallothioneins, and matrix metalloproteinases (MMPs) are potential biomarkers for predicting the metastatic ability of oral cancer [4].

The tissue inhibitor metalloproteinase-3 (TIMP3) is a member of the TIMP family. TIMP3 has a broad metalloproteinase inhibitory ability against MMPs, a disintegrin and metalloproteinase (ADAM), and 
ADAM with thrombospondin domain (ADAM-TS) families [5, 6]. TIMP3 influences cancer progression, and TIMP3 deregulation has been reported in several cancers [7-10]. Bodnar et al. reported that TIMP3 expression was significantly correlated with lymph node metastases in the Laryngeal squamous cell carcinoma [10]. Furthermore, in patients with head and neck squamous cell carcinoma (HNSCC), TIMP3 hypermethylation is associated with a risk of second primary carcinoma [11]. Moreover, TIMP3 hypermethylation has been reported in approximately $90 \%$ of all clinical T1 and T2 OSCC cases [12]. Our previous study also reported that the TIMP3 polymorphism rs9862 is associated with large tumor size in OSCC [8]. In addition, high TIMP3 mRNA levels significantly reduced overall survival in patients with HNSCC [13]. However, few studies have examined plasma TIMP3 levels in patients with OSCC. In this study, we investigated plasma TIMP3 levels in patients with OSCC and evaluated the association of TIMP3 with OSCC progression.

\section{Materials and Methods}

\section{Patient Specimens}

We recruited 450 OSCC male patients (mean age 55.36 years) from Chung Shan Medical University Hospital in Taichung and Changhua Christian Hospital in Changhua, Taiwan between 2008 and 2014. Demographic characteristics and medical information of the OSCC patients, including tumor stage, tumor, node, and metastasis (TNM) status, and cell differentiation was obtained from their medical records. Patients with OSCC were clinically staged at the time of diagnosis according to the TNM staging system described in the seventh edition of the staging manual by the American Joint Committee on Cancer Staging Manual. All blood samples were collected from OSCC patients and placed in tubes containing EDTA. After immediate centrifugation at $3000 \mathrm{rpm}$, the supernatants were stored at $-80^{\circ} \mathrm{C}$. This study was approved by the Institutional Review Board of Chung Shan Medical University Hospital (CSMUH No: CS13220), and informed written consent to participate in the study was obtained from each participant. Clinical characteristics of patients are summarized in Table 1.

\section{Quantitative Analysis of Plasma TIMP3 Level}

The TIMP3 levels in the plasma samples were analyzed using a TIMP3 (MIG-5) Human ELISA Kit (Abcam, Cambridge, MA, USA). Briefly, $100 \mu \mathrm{L}$ of prepared standards and diluted samples were added to the appropriate wells of an ELISA plate and incubated at $37^{\circ} \mathrm{C}$ for 90 minutes, then $100 \mu \mathrm{L}$ of $1 \mathrm{X}$ Biotinylated anti-human TIMP3 antibody was added into each well. After washing three times with $300 \mu \mathrm{L}$ TBS, $100 \mu \mathrm{L}$ of $1 \mathrm{X}$ Avidin-Biotin-Peroxidase Complex working solution was added to the wells. The wells were then washed again and filled with $90 \mu \mathrm{L}$ of TMB color developing agent at $37^{\circ} \mathrm{C}$ in the dark for 20 minutes. Finally, $100 \mu \mathrm{L}$ of prepared TMB Stop Solution was added to each well and absorbance was measured at $450 \mathrm{~nm}$ by using a microtest plate spectrophotometer. TIMP3 levels were quantified with a calibration curve by using human TIMP3 as a standard.

Table 1. Demographic characteristics and clinical features of OSCC patients.

\begin{tabular}{ll}
\hline Variables & OSCC (n $=450)$ \\
\hline Age (years) & $55.36 \pm 10.84$ \\
Gender & \\
Male & $438(97.3 \%)$ \\
Female & $12(2.7 \%)$ \\
Smoking status & \\
No & $56(12.4 \%)$ \\
Yes & $394(87.6 \%)$ \\
Drinking status & \\
No & $215(47.8 \%)$ \\
Yes & $235(52.2 \%)$ \\
Betel nuts chewing & \\
No & $97(21.6 \%)$ \\
Yes & $353(78.4 \%)$ \\
Cancer location & \\
Buccal mucosa & $159(35.3 \%)$ \\
Tongue & $135(30.0 \%)$ \\
Gingiva & $73(16.2 \%)$ \\
Others & $83(18.5 \%)$ \\
Stage & \\
I & $123(27.3 \%)$ \\
II & $80(17.8 \%)$ \\
III & $43(9.6 \%)$ \\
IV & $204(45.3 \%)$ \\
Tumor T status & \\
T1 & $147(32.7 \%)$ \\
T2 & $122(27.1 \%)$ \\
T3 & $38(8.4 \%)$ \\
T4 & $143(31.8 \%)$ \\
Lymph node status & \\
N0 & $295(65.6 \%)$ \\
N1 & $50(11.1 \%)$ \\
N2 & $101(22.4 \%)$ \\
N3 & $4(0.9 \%)$ \\
Metastasis & \\
M0 & $448(99.6 \%)$ \\
M1 & $2(0.4 \%)$ \\
Well differentiated & $60(13.3 \%)$ \\
Moderately or poorly differentiated & $390(86.7 \%)$ \\
\hline
\end{tabular}

\section{Expression analysis of The Cancer Genome Atlas OSCC data}

TIMP3 normalized expression data and associated clinical data were obtained from The Cancer Genome Atlas (TCGA; URL: https://tcga-data.nci.nih.gov/tcga/), which corresponds to the HNSCC dataset $(n=520)$. Samples 
filtered involved only one of six oral cancer subtypes (alveolar ridge, base of tongue, buccal mucosa, floor of mouth, oral cavity, oral tongue; filtered oral cancer dataset size: $\mathrm{n}=328$ ). Scatter plots of the expression values were generated with respect to the pathological tumor stage and TNM status for TIMP3.

\section{Statistical Analysis}

Values were expressed as means \pm SD. The statistical significance of the means for TIMP3 was determined using the Mann-Whitney Rank sum test between groups. The significances of differences between means were calculated using a Student $t$ test. Statistical significance was set at $p<0.05$. Analyses were performed using SPSS 16.0 statistical software (SPSS Inc., Chicago, IL, USA).

\section{Results}

\section{Demographic data}

In total, 450 patients with OSCC were included in this study. Table 1 presents the demographic data, tumor stage, TNM status, and tumor differentiation status of the patients. Of the patients, $87.6 \%$ smoked, $52.2 \%$ consumed alcohol, and $78.4 \%$ chewed betel nut. Tumors were located in the buccal mucosa $(n=159)$, tongue $(n=135)$, gingiva $(n=73)$, and other parts $(n=$ 83).

\section{Correlation between plasma TIMP3 levels and clinicopathological characteristics of patients}

Plasma TIMP3 levels are presented in Figure 1. The mean plasma TIMP3 level was significantly lower in patients with OSCC than in controls $(3845.0 \pm 167.8$ pg/mL vs. $11289.9 \pm 952.1 \mathrm{pg} / \mathrm{mL}$; $<$ < 0.001) (Figure 1A). The mean plasma TIMP3 level was significantly lower in stage II patients $(2966.1 \pm 300.7 \mathrm{pg} / \mathrm{mL})$ than in stage I patients $(4154.8 \pm 396.4 \mathrm{pg} / \mathrm{mL})(\mathrm{p}=0.031)$, and the mean plasma TIMP3 level was significantly higher in stage IV patients $(4066.3 \pm 229.9 \mathrm{pg} / \mathrm{mL})$ than in stage II patients $(p=0.008$; Figure $1 B)$. Furthermore, the mean plasma TIMP3 level was significantly lower in the T2 status (3362.2 \pm 252.6 $\mathrm{pg} / \mathrm{mL})$ than in the T4 status $(4305.3 \pm 293.5 \mathrm{pg} / \mathrm{mL})$ $(p=0.017$; Figure 1C). Moreover, the mean plasma TIMP3 level was significantly lower in N1 (2727.9 \pm $318.4 \mathrm{pg} / \mathrm{mL})$ than in N0 $(4085.1 \pm 225.9 \mathrm{pg} / \mathrm{mL})$ $(p=0.017)$, and the mean plasma TIMP3 level was significantly higher in $\mathrm{N} 2(3710.7 \pm 303.3 \mathrm{pg} / \mathrm{mL})$ than in N1 ( $p=0.045$; Figure 1D). The AUC of using TIMP3 as diagnostic biomarkers for OSCC was $0.835(95 \%$ $\mathrm{CI}=0.7839-0.8867 ; \mathrm{p}<0.0001)$. A level of $4258.5 \mathrm{pg} / \mathrm{mL}$ (the highest sum of sensitivity and specificity) was determined to be the most efficient threshold and we set this level as the cutoff point. The sensitivity and specificity of the assay was $69.6 \%$ and $84.4 \%$ (Figure. $1 \mathrm{E})$.

Table 2 presents the correlation between plasma TIMP3 levels and clinicopathological characteristics. The TIMP3 plasma levels (low level and high level) were divided according to the mean value of total TIMP3 plasma levels in OSCC patients. As shown in Table 2, high TIMP3 plasma levels were significantly associated with the tumor stage and $\mathrm{T}$ status. The percentage of stage IV patients with high TIMP3 plasma levels was higher than that of those with stage I, II and III.

Table 2. Correlation between plasma levels of TIMP-3 and clinicopathological parameters in 450 OSCC patients.

\begin{tabular}{|c|c|c|c|}
\hline & TIMP-3 levels & & $p$ value \\
\hline Variables & Low levels & High levels & \\
\hline \multicolumn{4}{|l|}{ Age (years) } \\
\hline$<55$ & $141(66.2 \%)$ & $72(33.8 \%)$ & \multirow[t]{2}{*}{0.768} \\
\hline$\geq 55$ & $160(67.5 \%)$ & $77(32.5 \%)$ & \\
\hline \multicolumn{4}{|l|}{ Gender } \\
\hline Male & $292(75.0 \%)$ & $146(25.0 \%)$ & \multirow[t]{2}{*}{0.545} \\
\hline Female & $9(66.7 \%)$ & $3(33.3 \%)$ & \\
\hline \multicolumn{4}{|l|}{ Smoking status } \\
\hline No & $37(66.1 \%)$ & $19(33.9 \%)$ & \multirow[t]{2}{*}{0.890} \\
\hline Yes & $264(67.0 \%)$ & $130(33.0 \%)$ & \\
\hline \multicolumn{4}{|l|}{ Drinking status } \\
\hline No & $144(67.0 \%)$ & $71(33.0 \%)$ & \multirow[t]{2}{*}{0.970} \\
\hline Yes & $157(66.8 \%)$ & $78(33.2 \%)$ & \\
\hline \multicolumn{4}{|l|}{ Betel nuts chewing } \\
\hline No & $67(69.1 \%)$ & $30(30.9 \%)$ & \multirow[t]{2}{*}{0.606} \\
\hline Yes & $234(66.3 \%)$ & $119(33.7 \%)$ & \\
\hline \multicolumn{4}{|l|}{ Cancer location } \\
\hline Buccal mucosa & $101(63.5 \%)$ & $58(36.5 \%)$ & \multirow[t]{4}{*}{0.648} \\
\hline Tongue & $95(70.4 \%)$ & $40(29.6 \%)$ & \\
\hline Gingiva & $50(68.5 \%)$ & $23(31.5 \%)$ & \\
\hline Others & $55(66.3 \%)$ & $28(33.7 \%)$ & \\
\hline \multicolumn{4}{|l|}{ Stage } \\
\hline I & $83(67.5 \%)$ & $40(32.5 \%)$ & \multirow[t]{4}{*}{$0.009^{*}$} \\
\hline II & $65(81.3 \%)$ & $15(18.8 \%)$ & \\
\hline III & $30(69.8 \%)$ & $13(30.2 \%)$ & \\
\hline IV & $123(60.3 \%)$ & $81(39.7 \%)$ & \\
\hline \multicolumn{4}{|l|}{ Tumor $\mathrm{T}$ status } \\
\hline $\mathrm{T} 1$ & $103(70.1 \%)$ & $44(29.9 \%)$ & \multirow[t]{4}{*}{$0.047^{*}$} \\
\hline $\mathrm{T} 2$ & $86(70.5 \%)$ & $36(29.5 \%)$ & \\
\hline $\mathrm{T} 3$ & $29(76.3 \%)$ & $9(23.7 \%)$ & \\
\hline $\mathrm{T} 4$ & $83(58.0 \%)$ & $60(42.0 \%)$ & \\
\hline \multicolumn{4}{|l|}{ Lymph node status } \\
\hline N0 & $192(65.1 \%)$ & $103(34.9 \%)$ & \multirow[t]{4}{*}{0.209} \\
\hline N1 & $40(80.0 \%)$ & $10(20.0 \%)$ & \\
\hline N2 & $66(65.3 \%)$ & $35(34.7 \%)$ & \\
\hline N3 & $3(75.0 \%)$ & $1(25.0 \%)$ & \\
\hline \multicolumn{4}{|l|}{ Metastasis } \\
\hline M0 & $328(66.7 \%)$ & $328(33.3 \%)$ & \multirow[t]{2}{*}{0.319} \\
\hline M1 & $2(100 \%)$ & $0(0 \%)$ & \\
\hline \multicolumn{4}{|l|}{ Cell differentiation } \\
\hline Well differentiated & $38(63.3 \%)$ & $22(36.7 \%)$ & \multirow[t]{2}{*}{0.530} \\
\hline $\begin{array}{l}\text { Moderately or poorly } \\
\text { differentiated }\end{array}$ & $263(67.4 \%)$ & $127(32.6 \%)$ & \\
\hline
\end{tabular}


(A)

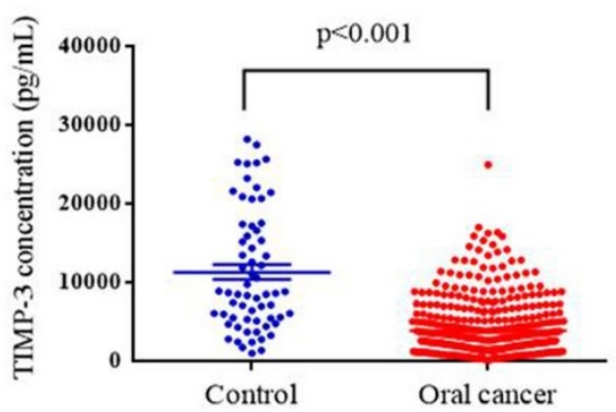

(C)

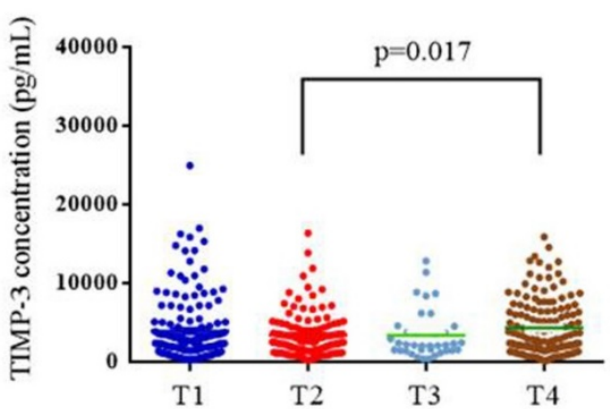

(B)

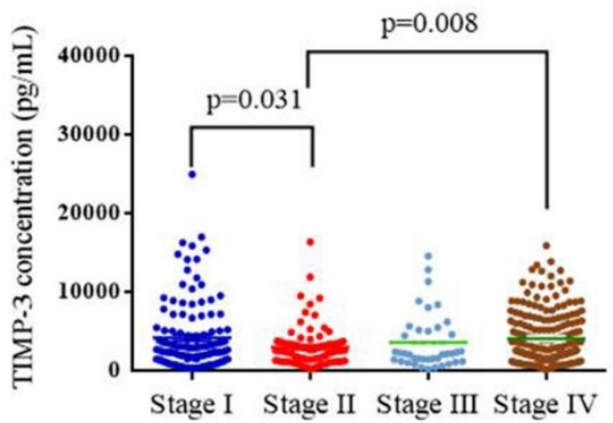

(D)

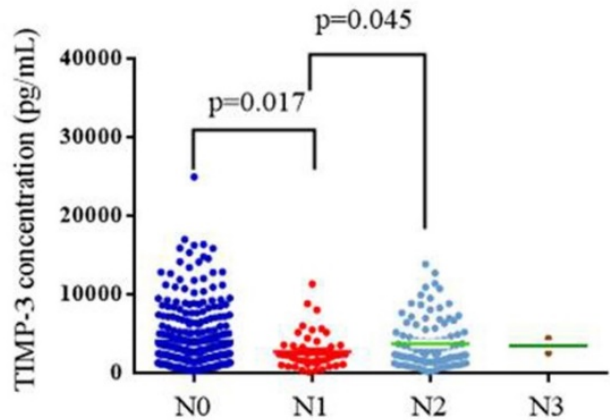

(E)

ROC Curve

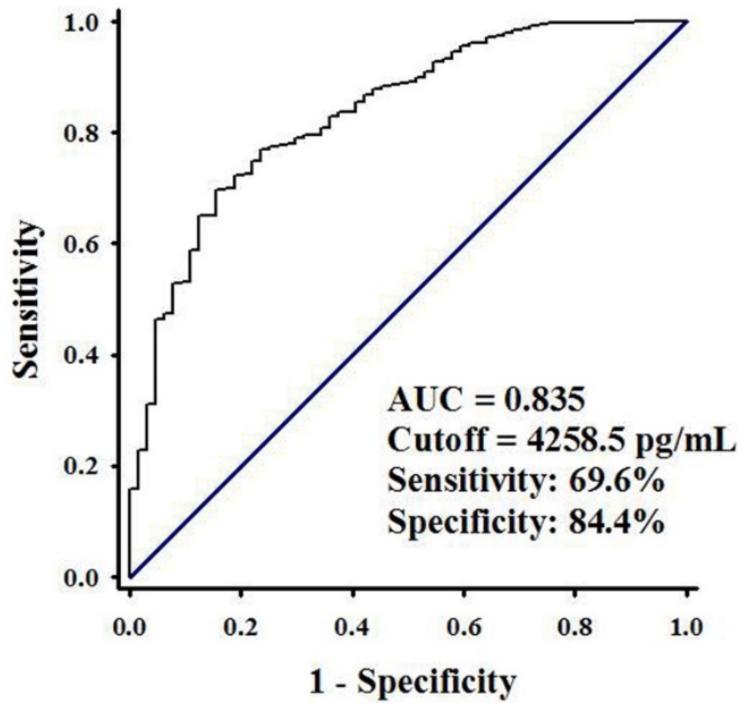

Figure 1. ELISA-determined plasma TIMP3 level of OSCC patients. (A) TIMP3 levels were compared according to normal control and OSCC patients. (B) TIMP3 levels were compared according to stage. (C) TIMP3 levels were compared according to tumor T status. (D) TIMP3 levels were compared according to N status. (E) ROC curve of plasma TIMP3 in discriminating between controls and patients with OSCC. AUC: area under curve.

Correlation between TIMP3 mRNA levels and clinicopathological characteristics of patients with OSCC from the Cancer Genome Atlas database

To verify our findings, TCGA OSCC database was used in this study. The TIMP3 mRNA levels, pathological stage, pathological $\mathrm{T}$ status, and pathological $\mathrm{N}$ status of OSCC and normal tissues were evaluated. Figure 2A shows the TIMP3 expression levels in different cancers. Data revealed no significant association between OSCC tissues and normal tissues (Figure 2B). Among the patients with OSCC, the relative TIMP3 mRNA level was 
significantly higher in stage IV patients than in stage III patients ( $p=0.014$; Figure 2C). However, the relative TIMP3 mRNA level was not significantly associated with the $\mathrm{T}$ status (Figure 2D). The relative
TIMP3 mRNA level was significantly higher in N2 than in $\mathrm{N} 0$ and $\mathrm{N} 1$ ( $\mathrm{p}=0.006$ and 0.044 , respectively; Figure 2E).

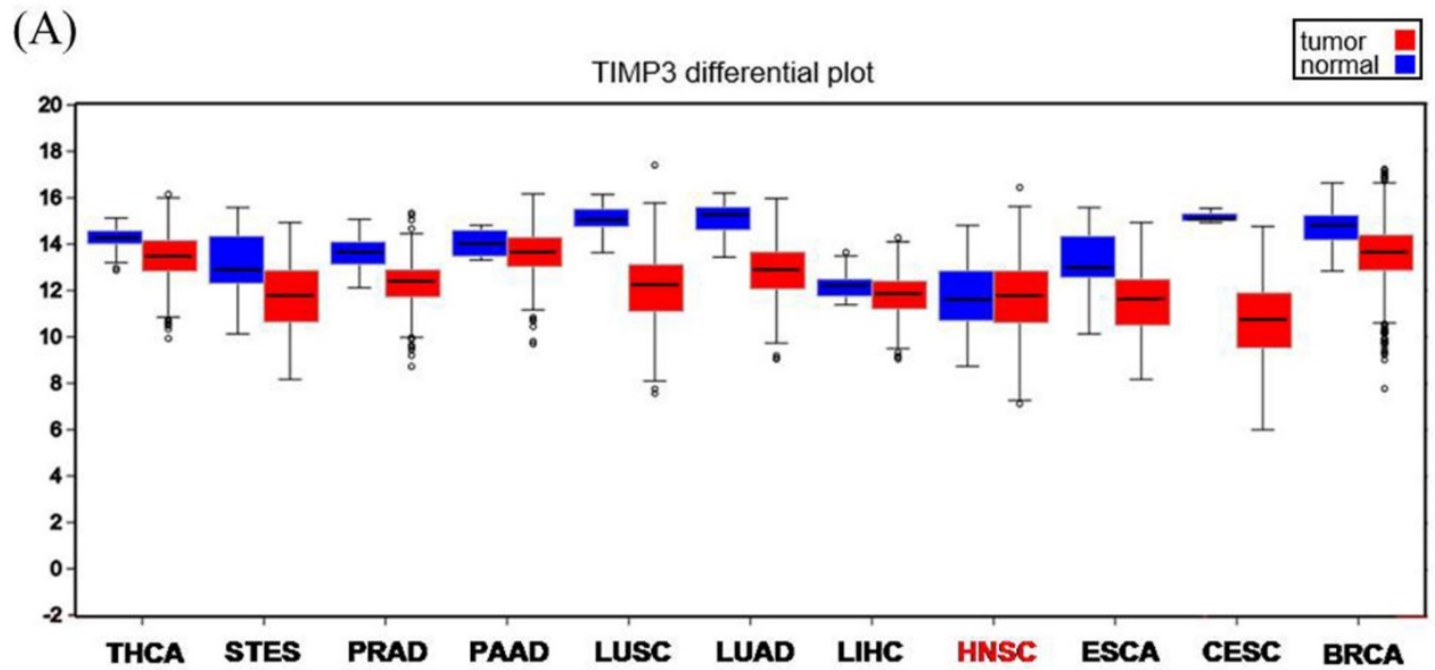

(B)

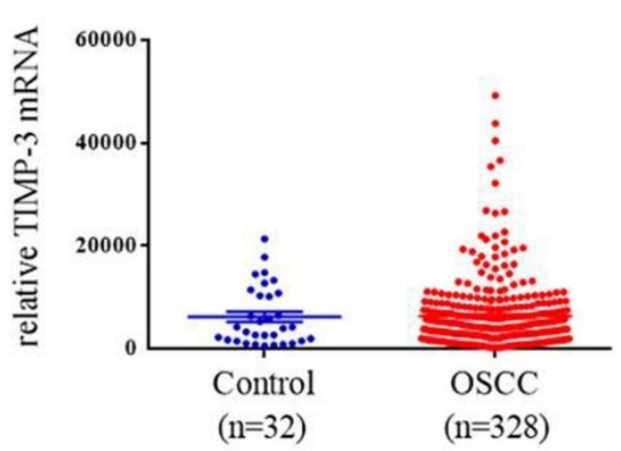

(D)

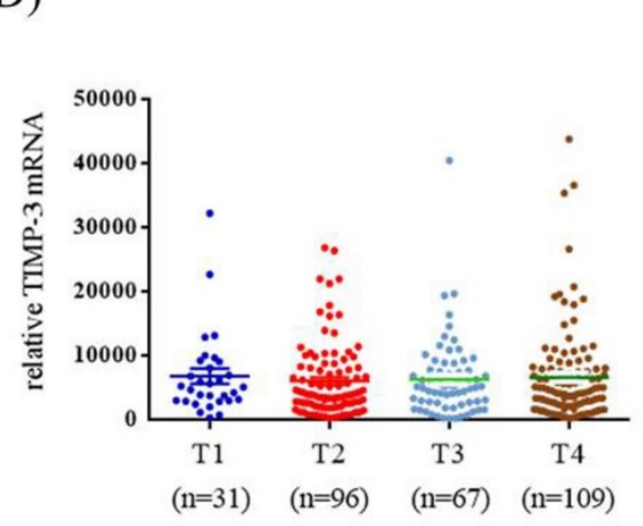

(C)

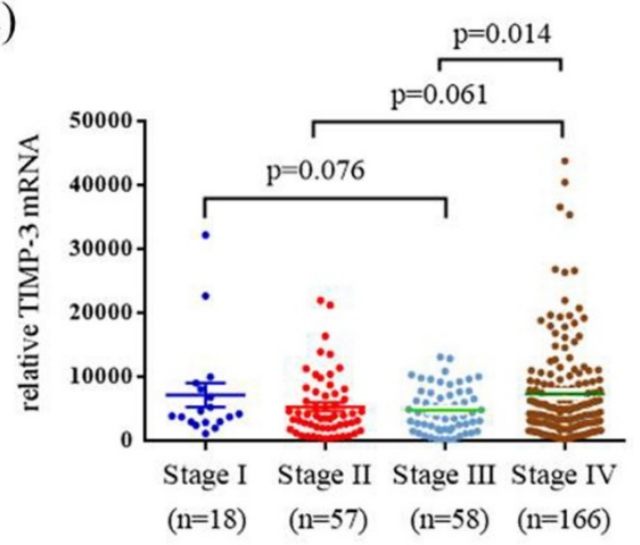

(E)

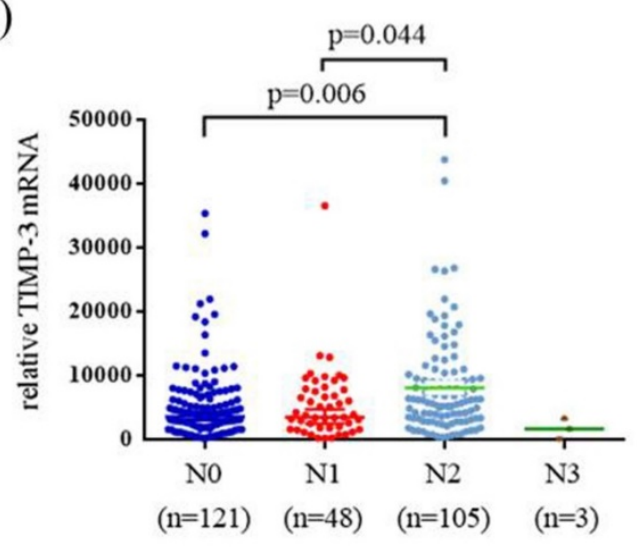

Figure 2. TIMP3 mRNA level of OSCC patients from TCGA database. (A) TIMP3 mRNA level of different type of cancer from The Broad Institute TCGA GDAC Firehose. (B) TIMP3 levels were compared according to normal people and OSCC patients. (C) TIMP3 levels were compared according to stage. (D) TIMP3 levels were compared according to tumor T status. (E) TIMP3 levels were compared according to N status. THCA: thyroid carcinoma. STES: stomach and esophageal carcinoma. PRAD: prostate adenocarcinoma. PAAD: pancreatic adenocarcinoma. LUSC: lung squamous cell carcinoma. LUAD: lung adenocarcinoma. LIHC: liver hepatocellular carcinoma. HNSC: head and neck squamous cell carcinoma. ESCA: esophageal carcinoma. CESC: cervical and endocervical cancers. BRCA: breast invasive carcinoma. 


\section{Discussion}

According to our research, this is the first study investigating the peripheral blood levels and potential roles of TIMP3 in OSCC. In this study, we observed that plasma TIMP3 levels were lower in patients with OSCC than in healthy controls. Moreover, plasma TIMP3 levels were significantly associated with the tumor stage and clinical $\mathrm{T}$ status in patients with OSCC.

The disruption of the balance between MMPs and TIMPs may contribute to malignant behavior in carcinogenesis [14-16]. Although TIMPs are known for their anticancer properties, other roles have also been reported $[17,18]$. For example, TIMP1 promotes cell proliferation of several cell types such as keratinocytes and fibroblasts [17, 18]. Unlike other TIMPs, TIMP3 has the ability to promote apoptosis through the stabilization of tumor necrosis factor receptors [19, 20]. Furthermore, TIMP3 exerts antiangiogenesis effects by blocking the binding of the VEGF to the VEGF receptor-2 [21]. Moreover, the restoration of TIMP3 in thyroid tumor cells increases cell adhesion ability [22]. In addition, Chen et al. reported that silencing of miR-221 could enhances the sensitivity of human OSCC cells to Adriamycin through upregulation of TIMP3 expression [23].

Different results of TIMP3 expression have been reported in different cancers [13, 24, 25]. Loss of TIMP3 expression in clear cell renal cell carcinoma was reported by Masson et al. [24] In addition, the downregulation of plasma TIMP3 in glioblastoma has been studied [25]. By contrast, Kornfeld et al. reported that TIMP3 mRNA levels were higher in the HNSCC stroma than in the stroma adjacent to the dysplastic or normal epithelia [13]. In our study, we observed that plasma TIMP3 levels were higher in healthy controls than in patients with OSCC. However, the results from TCGA database showed that TIMP3 mRNA levels were not significantly different in patients with OSCC tissue than in healthy controls. Additional studies with a high number of healthy controls are warranted.

Loss of TIMP3 in cancer may be due to genetic or epigenetic mechanisms. Genetic mechanisms include gene mutation, polymorphism, deletion, and copy number changes. Our previous data indicated that TIMP3 polymorphism rs9862 $\mathrm{T} / \mathrm{T}$ carriers have significantly highly plasma levels of TIMP3 compared with $\mathrm{C} / \mathrm{C}$ carriers [8]. Epigenetic mechanisms such as noncoding RNAs, histone modification, and DNA methylation can regulate gene expression without changing DNA sequence. In human gastric cancer cell lines, loss of TIMP3 protein expression is closely correlated with hypermethylation of TIMP3 in the region near the transcription start site [26]. Another study also revealed that TIMP3 protein expression was downregulated by miR-21 in human cholangiocarcinoma [27]. However, our data did not show the type of mechanisms that regulate TIMP3 plasma levels. In the future, we will further investigate mechanisms that regulate the loss of TIMP3 in OSCC patients.

OSCC may progress from an early stage to an advanced stage within a very short period, which hampers the early diagnosis of OSCC. Clinical specimens from tissues, saliva, and serum may facilitate the early detection of OSCC progression. For example, IL-6, which is correlated with the recurrence of OSCC can be detected in saliva [28]. However, some enzymes such as MMPs that were associated with tumor metastasis may not be detectable in saliva because of their low concentration [29]. Serum or plasma detection is also a useful method for discovering disease biomarkers because measuring biomarkers in blood is simple, convenient, and noninvasive $[30,31]$. Therefore, many plasma proteins have been evaluated as potential biomarkers for predicting OSCC progression. For example, plasma lipocalin-2 (LCN2) levels and the LCN2/matrix metallopeptidase 9 complex were significantly correlated with large tumor size in patients with OSCC [32]. Moreover, Singh et al. indicated a positive correlation between plasma MMP-2, TIMP-1, and TIMP-2 levels and lymph node involvement, stage, and tumor differentiation [33]. In this study, we suggested that TIMP3 is a favorable biomarker for detecting the tumor stage and $\mathrm{T}$ status in patients with OSCC.

TIMP3 has been reported to play a crucial role in cancer carcinogenesis. The restoration of TIMP3 in colorectal cancer cells suppresses tumor growth [34]. Furthermore, TIMP3 transfection suppresses the invasive and metastatic capacity in the hepatocellular carcinoma cell line [35]. Moreover, TIMP3 expression is associated with colon carcinoma differentiation [36]. In this study, plasma TIMP3 levels were significantly associated with the tumor stage and $\mathrm{T}$ status. We demonstrated that TIMP3 plasma levels were downregulated in stage II and then increased in stage IV. Similarly, TIMP3 plasma levels decreased in $\mathrm{T} 2$ and then increased in T4. With respect to the $\mathrm{N}$ status, TIMP3vplasma levels decreased in N1 and then increased in N2. To verify our findings, we also evaluated the association between TIMP3 mRNA levels and pathological stage and TNM in TCGA OSCC database. Similar to our ELISA data, TIMP3 mRNA levels decreased in stages II and III and then increased in stage IV. Furthermore, TIMP3 mRNA levels were also higher in N2 compared with N1. 
However, TCGA OSCC database did not show a significant association between TIMP3 mRNA levels and $\mathrm{T}$ status.

Our study possesses certain limitations that should be addressed. First, the sample size of healthy controls was inadequate. Second, TCGA database does not contain data regarding betel nut consumption in patients with OSCC; moreover, most of the data in TCGA is derived from Caucasian individuals. Third, we did not investigate the function of TIMP3 in vitro and in vivo. In our future work, we plan to recruit more healthy controls and patients with OSCC. Furthermore, we plan to transfect the TIMP3 overexpression vector into the OSCC cell line for evaluating the function of TIMP3 in cell proliferation and mobility. Moreover, the TIMP3-stable OSCC cell line will be injected directly into the anterior tongue of nude mice to confirm tumor growth, local invasion, and regional metastasis.

In summary, we observed that plasma TIMP3 levels were significantly associated with the tumor stage and $\mathrm{T}$ status in patients with OSCC. Plasma TIMP3 levels were downregulated in stage II and then increased in stage IV, and a similar tendency was observed for the T status. Plasma TIMP3, a secreted protein, plays a crucial role in carcinogenesis and may act as a potential biomarker for tumor progression in OSCC.

\section{Acknowledgements}

This study was supported by a research grant from the National Science Council, Taiwan (MOST 103-2314-B-040-019). This study was also supported by a research grant from Health and welfare surcharge of tobacco products, Ministry of Health and Welfare (MOHW103-TD-B-111-08; MOHW104-TDUB-212-124-005 and MOHW105-TDU-B-212-134002).

\section{Conflict of interest}

There are no conflicts of interest to declare.

\section{References}

[1] Chung TT, Pan MS, Kuo CL, Wong RH, Lin CW, Chen MK and Yang SF. Impact of RECK gene polymorphisms and environmental factors on oral cancer susceptibility and clinicopathologic characteristics in Taiwan. Carcinogenesis 2011; 32: 1063-1068.

[2] Scully C and Porter S. ABC of oral health. Oral cancer. Bmj 2000; 321: 97-100.

[3] Kozomara R, Jovic N, Magic Z, Brankovic-Magic M and Minic V. p53 mutations and human papillomavirus infection in oral squamous cell carcinomas: correlation with overall survival. J Craniomaxillofac Surg 2005; 33: $342-348$.

[4] Noguti J, De Moura CF, De Jesus GP, Da Silva VH, Hossaka TA, Oshima CT and Ribeiro DA. Metastasis from oral cancer: an overview. Cancer Genomics Proteomics 2012; 9: 329-335.

[5] Woessner JF, Jr. That impish TIMP: the tissue inhibitor of metalloproteinases-3. J Clin Invest 2001; 108: 799-800.

[6] Brew K and Nagase H. The tissue inhibitors of metalloproteinases (TIMPs): an ancient family with structural and functional diversity. Biochim Biophys Acta 2010; 1803: 55-71.

[7] Kmiecik AM, Pula B, Suchanski J, Olbromski M, Gomulkiewicz A, Owczarek T, Kruczak A, Ambicka A, Rys J, Ugorski M, Podhorska-Okolow M and Dziegiel P. Metallothionein-3 Increases Triple-Negative Breast Cancer Cell
Invasiveness via Induction of Metalloproteinase Expression. PLoS One 2015; 10: $\mathrm{e} 0124865$.

[8] Su CW, Huang YW, Chen MK, Su SC, Yang SF and Lin CW. Polymorphisms and Plasma Levels of Tissue Inhibitor of Metalloproteinase-3: Impact on Genetic Susceptibility and Clinical Outcome of Oral Cancer. Medicine (Baltimore) 2015; 94: e2092.

[9] Tan LZ, Song Y, Nelson J, Yu YP and Luo JH. Integrin alpha7 binds tissue inhibitor of metalloproteinase 3 to suppress growth of prostate cancer cells. Am J Pathol 2013; 183: 831-840.

[10] Bodnar M, Szylberg L, Kazmierczak W and Marszalek A. Tumor progression driven by pathways activating matrix metalloproteinases and their inhibitors. J Oral Pathol Med 2015; 44: 437-443.

[11] Rettori MM, de Carvalho AC, Longo AL, de Oliveira CZ, Kowalski LP, Carvalho AL and Vettore AL. TIMP3 and CCNA1 hypermethylation in HNSCC is associated with an increased incidence of second primary tumors. J Transl Med 2013; 11: 316.

[12] Arantes LM, de Carvalho AC, Melendez ME, Centrone CC, Gois-Filho JF, Toporcov TN, Caly DN, Tajara EH, Goloni-Bertollo EM and Carvalho AL. Validation of methylation markers for diagnosis of oral cavity cancer. Eur J Cancer 2015; 51: 632-641.

[13] Kornfeld JW, Meder S, Wohlberg M, Friedrich RE, Rau T, Riethdorf L, Loning $\mathrm{T}$, Pantel K and Riethdorf S. Overexpression of TACE and TIMP3 mRNA in head and neck cancer: association with tumour development and progression. Br J Cancer 2011; 104: 138-145.

[14] Jiang Y, Goldberg ID and Shi YE. Complex roles of tissue inhibitors of metalloproteinases in cancer. Oncogene 2002; 21: 2245-2252.

[15] Ho HY, Lin CW, Chien MH, Reiter RJ, Su SC, Hsieh YH and Yang SF. Melatonin suppresses TPA-induced metastasis by downregulating matrix metalloproteinase-9 expression through JNK/SP-1 signaling in nasopharyngeal carcinoma. J Pineal Res 2016; 61: 479-492.

[16] Su SC, Hsieh MJ, Yang WE, Chung WH, Reiter RJ and Yang SF. Cancer metastasis: mechanisms of inhibition by melatonin. J Pineal Res 2016; doi: 10.1111/jpi.12370

[17] Bertaux B, Hornebeck W, Eisen AZ and Dubertret L. Growth stimulation of human keratinocytes by tissue inhibitor of metalloproteinases. J Invest Dermatol 1991; 97: 679-685.

[18] Hayakawa T, Yamashita K, Tanzawa K, Uchijima E and Iwata K. Growth-promoting activity of tissue inhibitor of metalloproteinases-1 (TIMP-1) for a wide range of cells. A possible new growth factor in serum. FEBS Lett 1992; 298: 29-32.

[19] Smith MR, Kung H, Durum SK, Colburn NH and Sun Y. TIMP-3 induces cell death by stabilizing TNF-alpha receptors on the surface of human colon carcinoma cells. Cytokine 1997; 9: 770-780.

[20] Ahonen M, Poukkula M, Baker AH, Kashiwagi M, Nagase H, Eriksson JE and Kahari VM. Tissue inhibitor of metalloproteinases-3 induces apoptosis in melanoma cells by stabilization of death receptors. Oncogene 2003; 22: 2121-2134.

[21] Qi JH, Ebrahem Q, Moore N, Murphy G, Claesson-Welsh L, Bond M, Baker A and Anand-Apte B. A novel function for tissue inhibitor of metalloproteinases-3 (TIMP3): inhibition of angiogenesis by blockage of VEGF binding to VEGF receptor-2. Nat Med 2003; 9: 407-415.

[22] Anania MC, Sensi M, Radaelli E, Miranda C, Vizioli MG, Pagliardini S, Favini E, Cleris L, Supino R, Formelli F, Borrello MG, Pierotti MA and Greco A. TIMP3 regulates migration, invasion and in vivo tumorigenicity of thyroid tumor cells. Oncogene 2011; 30: 3011-3023.

[23] Chen D, Yan W, Liu Z, Zhang Z, Zhu L, Liu W, Ding X, Wang A and Chen Y. Downregulation of miR-221 enhances the sensitivity of human oral squamous cell carcinoma cells to Adriamycin through upregulation of TIMP3 expression. Biomed Pharmacother 2016; 77: 72-78.

[24] Masson D, Rioux-Leclercq N, Fergelot P, Jouan F, Mottier S, Theoleyre S, Bach-Ngohou K, Patard JJ and Denis MG. Loss of expression of TIMP3 in clear cell renal cell carcinoma. Eur J Cancer 2010; 46: 1430-1437.

[25] Sreekanthreddy P, Srinivasan H, Kumar DM, Nijaguna MB, Sridevi S, Vrinda M, Arivazhagan A, Balasubramaniam A, Hegde AS, Chandramouli BA, Santosh V, Rao MR, Kondaiah P and Somasundaram K. Identification of potential serum biomarkers of glioblastoma: serum osteopontin levels correlate with poor prognosis. Cancer Epidemiol Biomarkers Prev 2010; 19: 1409-1422.

[26] Kang SH, Choi HH, Kim SG, Jong HS, Kim NK, Kim SJ and Bang YJ. Transcriptional inactivation of the tissue inhibitor of metalloproteinase- 3 gene by dna hypermethylation of the 5'-CpG island in human gastric cancer cell lines. Int J Cancer 2000; 86: 632-635.

[27] Selaru FM, Olaru AV, Kan T, David S, Cheng Y, Mori Y, Yang J, Paun B, Jin Z, Agarwal R, Hamilton JP, Abraham J, Georgiades C, Alvarez H, Vivekanandan P, Yu W, Maitra A, Torbenson M, Thuluvath PJ, Gores GJ, LaRusso NF, Hruban R and Meltzer SJ. MicroRNA-21 is overexpressed in human cholangiocarcinoma and regulates programmed cell death 4 and tissue inhibitor of metalloproteinase 3. Hepatology 2009; 49: 1595-1601.

[28] SahebJamee M, Eslami M, AtarbashiMoghadam F and Sarafnejad A. Salivary concentration of TNFalpha, IL1 alpha, IL6, and IL8 in oral squamous cell carcinoma. Med Oral Patol Oral Cir Bucal 2008; 13: E292-295.

[29] Wu JY, Yi C, Chung HR, Wang DJ, Chang WC, Lee SY, Lin CT, Yang YC and Yang WC. Potential biomarkers in saliva for oral squamous cell carcinoma. Oral Oncol 2010; 46: 226-231. 
[30] Ni YH, Ding L, Hu QG and Hua ZC. Potential biomarkers for oral squamous cell carcinoma: proteomics discovery and clinical validation. Proteomics Clin Appl 2015; 9: 86-97.

[31] Brinkman BM and Wong DT. Disease mechanism and biomarkers of oral squamous cell carcinoma. Curr Opin Oncol 2006; 18: 228-233.

[32] Lin CW, Tseng SW, Yang SF, Ko CP, Lin CH, Wei LH, Chien MH and Hsieh YS. Role of lipocalin 2 and its complex with matrix metalloproteinase-9 in oral cancer. Oral Dis 2012; 18: 734-740.

[33] Singh RD, Haridas N, Patel JB, Shah FD, Shukla SN, Shah PM and Patel PS. Matrix metalloproteinases and their inhibitors: correlation with invasion and metastasis in oral cancer. Indian J Clin Biochem 2010; 25: 250-259.

[34] Lin H, Zhang Y, Wang H, Xu D, Meng X, Shao Y, Lin C, Ye Y, Qian H and Wang S. Tissue inhibitor of metalloproteinases-3 transfer suppresses malignant behaviors of colorectal cancer cells. Cancer Gene Ther 2012; 19: 845-851.

[35] Zhang H, Wang YS, Han G and Shi Y. TIMP-3 gene transfection suppresses invasive and metastatic capacity of human hepatocarcinoma cell line HCC-7721. Hepatobiliary Pancreat Dis Int 2007; 6: 487-491.

[36] Bai YX, Yi JL, Li JF and Sui H. Clinicopathologic significance of BAG1 and TIMP3 expression in colon carcinoma. World J Gastroenterol 2007; 13: 3883-3885. 